\title{
The Prevalence and Occurrence of Candida albicans Among the Students of MAHSA University ${ }^{\dagger}$
}

\section{Pazhayakath Thevarkattil Mohamed Javad 1,*, Kiranpal Kaur ${ }^{1}$, Muruganandham Chandramohan ${ }^{1}$, Ponnaiah Paulraj ${ }^{1}$, Tunasamy Ketharin ${ }^{1}$, Pattammadath Sajeesh ${ }^{1}$, Keeyari Purayil Sajna ${ }^{1}$, Antony V. Samrot $^{1}$, Iyyappan Petchi ${ }^{1}$}

1 Department of Biosciences, Faculty of Medicine, MAHSA University, Bandar Saujana Putra, Selangor Darul Ehsan, Malaysia

* Correspondence: javad@mahsa.edu.my;

$\dagger$ Presented at International e-Conference on Bioengineering for Health and Environment (ICBHE 2020)

Received: 5.07.2020; Revised: 10.07.2020; Accepted: 12.07.2020; Published: 15.07.2020

\begin{abstract}
The study is done to identify the prevalence and occurrence of Candida albicans among the students of MAHSA University. It is also done to perform a cross-sectional survey by means of a selfadministered questionnaire to assess the oral health knowledge, attitude, and practice (KAP) among the study group. Furthermore, it is done to determine the association of knowledge with attitude, oral health practices, and the prevalence of Candida albicans with the study group. The spores of Candida are a commensal, harmless form of a fungus that becomes invasive and pathogenic pseudohyphae when there is a disruption in the balance of flora. The infection that is caused by the yeast Candida albicans or even other candida species is candidiasis. Questionnaire on oral health was handed out to the students at random in MAHSA University, and upon that, samples are collected by taking their unstimulated saliva and are then pipetted on Sabouraud's dextrose agar. These agar plates are then kept in an incubator at $37^{\circ} \mathrm{C}$ for 2 days. After 2 days, the agar plates are then checked for any growth, and if there is the growth seen, gram stain and germ tube tests are done. It was seen that out of 100 samples collected, $40 \%$ were positive for Candida albicans, and $60 \%$ were negative for Candida albicans. And out of the percentage of positive samples, $26 \%$ were males, and $14 \%$ were females Candida albicans is the species most frequently implicated in the oral cavity, and it is important to take care of the oral cavity.
\end{abstract}

Keywords: Candida albicans; pathogenic pseudohyphae; Saliva and Questionnaire.

(C) 2020 by the authors. This article is an open-access article distributed under the terms and conditions of the Creative Commons Attribution (CC BY) license (https://creativecommons.org/licenses/by/4.0/).

\section{Funding}

This research received no external funding.

\section{Acknowledgments}

This research has no acknowledgment.

\section{Conflicts of Interest}

The authors declare no conflict of interest. 